\title{
Effect of feeding separately grain maize silage with or without cobs and protein supplement on bacon pig performance
}

\author{
J. CASTAING ${ }^{(1)}$, R. COUDURE ${ }^{(1)}$, F. GROSJEAN (2) \\ (1) A.G.P.M., 122, boulevard Tourasse, 64000 Pau. \\ (2) I.T.C.F., 8, avenue du Président-Wilson, 75116 Paris.
}

Two trials were made to study the effect of feeding separately grain maize silage and protein supplement. In each trial, 48 castrated males and 48 females were fed according to a feeding pattern including 14 meals a week. Silages used were either based on moist grain maize (MGS) or on grain maize with cobs (MGR). In both trials silage and supplement were fed either mixed at the two daily meals or separately, i.e., silage at the evening meal and supplement at the morning meal. In the first trial, the proportion of silage ranged around $75 \%$ and that of the supplement (soybean meal + minerals and vitamins) around $25 \%$. In the second trial, the supplement was composed of soybean meal with maize grain and represented $50 \%$ of the daily feed ration.

There was no interaction between the feeding pattern and the type of silage (MGS, MGR) on growth performance. Feeding separately the supplement at the level of $25 \%$ (1st trial) depressed the performance of pigs by $10.8 \%$ during the growing period and by $7.4 \%$ during the finishing period. Over the whole fattening period the reduction reached $9.2 \%$ with feed conversion ratios of 3.03 and 3.22 for MGS and MGR diets given separately versus 2.76 and 2.96 for MGS and MGR diets mixed with the supplement. Feeding separately the supplement at the level of $50 \%$ (2nd trial) reduced growth rate by $4.2 \%$ during the growing period and by $2.7 \%$ during the finishing period. Over the whole fattening period the reduction reached $3.6 \%$ with feed conversion ratios of 2.95 and 3.18 for MGS and MGR given separately versus 2.85 and 3.06 for MGS and MGR given with the supplement. In both trials, separate feeding tented to reduce carcass yield by 0.5 point. Carcass quality was little affected by the feeding pattern with MGR diet. By contrast, it was reduced with MGS fed separately. Accordingly, it is not recommended to feed silage and supplement separately.

\section{Utilization of sorghums with different tannin contents by the weaned piglet}

\author{
J. FEKETE ${ }^{(1)}$, J. CASTAING ${ }^{(2)}$
}

(1) I.T.C.F., 8, avenue du Président-Wilson, 75116 Paris.

(2) A.G.P.M., 122, boulevard Tourasse, 64000 Pau.

Two trials involving 936 weaned piglets between 9.5 and $24 \mathrm{~kg}$ were conducted to compare the feeding value of sorghums with a low or a medium tannin content to that of maize. Two groups of sorghums Argence (2 and $1.4 \mathrm{~g}$ tannin $/ \mathrm{kg} \mathrm{MS}$ ) and NK 121 (10 and $7.2 \mathrm{~g}$ tannin $/ \mathrm{kg}$ MS) were incorporated in replacement for maize in the control diet.

Daily mean feed intake was not affected by sorghum whatever the variety studied. Growth rate was only slightly depressed $(-3 \%)$ with sorghum NK 121 containing $10 \mathrm{~g}$ tannin. It was similar with diets based on sorghums Argence and NK 121 containing $7 \mathrm{~g}$ tannins and with maizebased diets.

There was no difference in the efficiency between sorghum-based and maize-based diets, except when sorghum contained $10 \mathrm{~g}$ of tannin. The efficiency was then reduced by $5 \%$.

It was concluded that low and medium tannin sorghums can be used in diets for weaned piglets in the same proportion as maize. 